\title{
Método de la consulta a la memoria colectiva y perspectivas de la investigación
}

\author{
Luis Francisco Rodríguez Manotas ${ }^{1}$ \\ Rubén Darío Hernández Cassiani ${ }^{2}$
}

\section{Introducción}

Es comprensible que insistan en medirnos con la misma vara con que se miden a sí mismos, sin recordar que los estragos de la vida no son iguales para todos, y que la búsqueda de la identidad propia es tan ardua y sangrienta para nosotros como lo fue para ellos. La interpretación de nuestra realidad con esquemas ajenos sólo contribuye a hacernos cada vez más desconocidos, cada vez menos libres, cada vez más solitarios (García Márquez, 1982).

La compleja realidad de la región Caribe, Colombia y la humanidad, reclaman renovar permanentemente los conocimientos del conjunto de acontecimientos y hechos que en su discurrir acaecen y marcan su devenir social, económico, político, territorial y ambiental.

Esta posibilidad de renovación y ampliación de los horizontes de conocimiento, está dada, siempre y cuando se recorran caminos en los cuales los sujetos sean las propias comunidades que, trascienden del papel de meros informantes y constituyen la razón de ser del proceso investigativo.

1 Doctorando en Cultura y Educación en América Latina. Especialista en Gestión en Centros Educativos. Licenciado en Ciencias Sociales. Director Académico Instituto Manuel Zapata Olivella. Correo: rodriguezmanotas@yahoo.com

2 Doctorado en Ciencias Sociales (en homologación). Magister en Filosofía Latinoamericana. Historiador. Docente Universidad Abierta y a Distancia (UNAD). Docente Maestría en Conflicto Social y Paz, Universidad de Cartagena. Director Instituto Manuel Zapata Olivella. Integrante del Proceso de Comunidades Negras. Correo: rubenhernandezca@hotmail.com 
De esta manera, se rompe con cualquier obstáculo epistemológico que divorcia y separa los actores principales de los propósitos y alcances trazados en el proceso investigativo, pero sobre todo se logra que los sujetos de las mismas, representados por la colectividad étnica y social, interioricen sus resultados, poniéndolo al servicio de sus aspiraciones transformacionales.

Cuando esto ocurre, la investigación se conecta realmente con un ideario de construcción social, adquiere sentido, en la medida que deja de ser una abstracción metafísica e insular y se convierte en un corpus de ideas incidente en la concreción de alternativas a situaciones problemáticas que afectan la vida de las colectividades.

Desde este punto de vista, adquieren los resultados de la investigación una dimensión comprensiva de realidades al servicio de idearios agenciados por sujetos de derechos colectivos organizados socialmente, a través de múltiples expresiones organizativas sociales, económicas, políticas, educativas, artísticas, entre otras, que encuentran en los productos de conocimientos generados, luces que despejan el camino de las tinieblas por los cuales transitan.

En esto se enmarca la intencionalidad del método de consulta a la memoria colectiva en clave de diálogo con otros horizontes metodológicos alternativos que se construyen a diario en múltiples escenarios académicos y sociales con el propósito de empoderarlos epistemológica y políticamente. En ese sentido, el artículo pasa revista a los antecedentes y fundamentos más importantes que lo definen, al igual que las fases y dispositivos técnicos que se requieren para llevar a feliz puerto cualquier iniciativa de investigación soportada en la lógica y racionalidad de los propios sujetos.

\section{El método de la consulta a la memoria colectiva como estrategia de investigación}

No deja de ser un verdadero desafío intentar definir realidades tan complejas, a veces, tan subjetivas, tan de constructo permanente, que la misma definición se convierte en una limitante de esa realidad rica y fuente por excelencia de creatividad e imaginación. Sin embargo, en este caso, trataremos de hacer una aproximación 
a lo que es el Método de la Consulta a la Memoria Colectiva, con el propósito de que los interesados en adelantar procesos investigativos alternativos, y realmente transformadores de mentalidades, recojan parte de nuestra experiencia a lo largo del proceso etnoeducativo en el Caribe continental colombiano.

Podríamos comenzar diciendo que, el método en cuestión es un dispositivo estratégico que se estructura desde unas necesidades sentidas al interior de una comunidad organizada, que al requerir salvaguardar su cultura propia y generar procesos de autorreconocimiento y movilización colectiva, diseña unas estrategias con el propósito de construir una herramienta metodológica para acceder a lo más profundo de su ser histórico-social, permitiéndose leerse a sí misma, entender el sentido de la forma cómo funciona el grupo, haciendo conciencia colectiva de que, durante y después de dicho proceso, se construye un método de investigación. Es imperativa la necesidad de hacer conciencia con la comunidad acerca de la construcción de un método que consulte a su memoria y permita recordar de manera colectiva su propia historia.

Todo lo necesario va fluyendo simultáneamente como un proceso dialéctico, a partir de las mismas etapas o fases del método que, en sí mismas dan como resultado el propio método. Esto hace que la investigación, y el método para desarrollarla, no sean una camisa de fuerza, sino un espacio de configuración o construcción del conocimiento de forma colectiva e individual.

Con lo anterior queremos decir, que la iniciativa de la investigación, parte de la misma comunidad, con la particularidad que, ésta se compromete en realizar dicha investigación, o sea, que ya no se trata del investigador encopetado, arrogante "experto" actor externo, con intereses ajenos a los del grupo, sino de cuadros comunitarios de líderes, académicos, manejadores de saberes ancestrales, estudiantes, maestros, que desde sus humildes roles, se proponen develar el sentido de su propia lógica. En otras palabras, la comunidad es sujeto de la investigación. Pero al mismo tiempo, estos grupos y sujetos comunitarios se asumen como objeto, fuente y método de esa investigación, ellos son los portadores de la memoria colectiva, por lo tanto, son quienes la ponen en disposición para ser 
procesada en los talleres, foros, conversatorios y en otros espacios, dispuestos para las jornadas de consulta a dicha memoria.

La búsqueda de un método comunitario que consulte a la memoria colectiva para entender el sentido de la lógica de mentalidad, o la manera cómo la comunidad organiza y expresa su diario vivir a través del tiempo, conlleva a que, al construir su historia colectiva, la comunidad descubre la dimensión de su identidad. La indagación colectiva dinamiza el sujeto histórico, porque la comunidad investiga asumiéndose como "sujeto-objeto", "método y fuente". Es sujeto porque se asume como investigadora, es fuente porque es la portadora de la memoria colectiva, y es método, porque lo construye desde su propia lógica de mentalidad.

Fals Borda (1998) sostiene que:

Por más que el antropólogo o sociólogo dijera que estaba participando o que era un observador participante, él seguía siendo el doctor; él controlaba la investigación: él disponía todo lo concerniente al trabajo investigativo, él era el sujeto de la investigación. Los otros eran clientes, eran objetos y, por lo tanto seres explotables de la investigación. Casi siempre, estos investigadores produjeron monografías o libros para promoverse ellos mismos o para sacar título, sin tomar en cuenta ni siquiera la necesidad de devolver ese conocimiento a quienes lo habían facilitado. Continuaba... esa diferencia tajante entre sujeto y objeto de investigación (p. 13).

El gran reto desde el método es acabar el "misterio de lo que significa el rompimiento del binomio sujeto-objeto. Es un misterio, porque no se sabe exactamente qué es lo que pasa con ello en el terreno..." (Fals Borda, 1998, p. 13)

Consideramos que es aquí donde está la clave del problema de la participación comunitaria en sus propios procesos investigativos que generen conciencia de identidad para su posicionamiento político e ideológico, ya sea como grupo étnico o como clase social marginada. De igual forma se va formando a partir de la práctica, la conciencia de sujeto investigador por parte de los actores comunitarios. 
Desde el punto de vista pedagógico, la construcción de un método de investigación, plantea la necesidad de indagar acerca del cómo entender la propia lógica de mentalidad para lograr conciencia sobre la capacidad de producir pensamiento y así aprender a leer con referentes propios.

Desde los ojos historiadores, el sentido de la lógica se convierte en lecturas de tiempos para poder entender la dimensión de transcurrir a través de los siglos. Entonces se inicia la búsqueda de la herramienta para captar la vida de los tiempos. Es el presente que mira e indaga hacia el pasado o hacia el futuro.

¿Dónde están los referentes propios? ¿Cómo entender el sentido de pertenencia desde la identidad y el reconocimiento? Para acciones más concretas dentro del mismo proceso de investigación las preguntas sobre la participación y la pertenencia se ubican en las propias necesidades de las comunidades. El sentido de pertenencia se puede ubicar en la participación colectiva en acciones para solucionar problemas de infraestructura, por ejemplo.

A través de este proceso de construcción de una herramienta metodológica, recuperamos la memoria colectiva, como una fuente documental viva que permite lecturas propias, y procesos autónomos, para tejer una síntesis desde la perspectiva de la identidad en el presente.

\section{Antecedentes del método de la consulta a la memoria colectiva}

En las tres últimas décadas los desarrollos de las Ciencias Sociales, con el propósito de romper con los viejos esquemas y visiones positivistas que han orientado el quehacer investigativo en nuestro país por largo tiempo, han dado como resultado nuevos métodos a partir de los cuales se pretende interpretar y transformar las realidades adversas.

Esta reflexión tiene un referente teórico importante en la crítica que realiza Paul Feyerabend (1984) en los años 70, recogido en su libro "Contra el método" y en el cual critica al método científico imperante y su intención de proponer reglas que guíen a los científicos en la tarea 
de elegir una teoría. Para Feyerabend, hallar esta serie sistemática de reglas es imposible. Mantilla (1999) interpreta acuciosamente estas intencionalidades y amplía las perspectivas cuando sostiene que:

La imposibilidad planteada por Feyerabend no es solo una imposibilidad epistemológica en la relación entre verdad y error universal, sino también una imposibilidad de orden socio-cultural por la diversidad de los seres humanos, así como también el grave problema ético que representa el hecho de ocultar que la práctica de la diversidad, menos que impedir el desarrollo del conocimiento, permite de mejor manera su avance y el reconocimiento de otros procesos igualmente legítimos de conocer el mundo (pp. 226-227).

Los recorridos metodológicos de Foucault, desde la visión arqueológica y genealógica, también dan pistas importantes al respecto, en ese sentido, McNay (1994) citado por Hall (1996) dice:

El pasaje critico en la obra de Foucault de un método arqueológico a un método genealógico contribuye en mucho, a hacer más concreto el formalismo un tanto vacío de sus primeros trabajos, lo cual se nota en especial en la vigorosa reintroducción del poder, que estaba ausente en el tratamiento más formal del discurso, en un lugar central y en las estimulantes posibilidades abiertas por la discusión foucultiana del carácter bilateral de la sujeccion/subjetivación (p. 28).

Más importante aún, en la medida que teorizan los impactos del colonialismo y ponen al desnudo los efectos catastróficos del eurocentrismo, los constructos teóricos con clara connotación política de Frantz Fanon, Cheikh Anta Diop, Samir Amin, Nkogo Ondo Nelson Mandela, Martin Luther King, Malcon X, recepcionados y profundizados en América Latina y el Caribe por Manuel Zapata Olivella, Rogelio Velásquez, Amín Cesaire, Eduardo Galeano y recientemente los exponentes del paradigma decolonial Enrique Dussell, Walter Mignolo, Aníbal Quijano, Arturo Escobar, Catherine 
Walsh y otros, se enmarcan epistemológicamente en la búsqueda de nuevos métodos de conocimiento de la realidad ${ }^{3}$.

Fruto de esa búsqueda, con la orientación de Fals Borda, emerge la IAP, el cual ha permitido revelar el sentido profundamente activo y participante de cualquier herramienta que esté dirigida a ampliar nuestros horizontes de conocimiento.

No obstante, los logros obtenidos con la aplicación de la IAP, la comunidad seguía siendo objeto de estudio a pesar de estar participando en el trabajo de investigación; así, el principio fundamental de la Investigación Acción Participativa -la comunidad en sí misma Sujeto-Objeto para lograr el sentido del método- sólo lograba la consulta desde los ojos del investigador y la comunidad quedaba iniciada en una expectativa de conocimiento.

Ante esta situación, en el marco del movimiento social afrocolombiano, más específicamente, desde la experiencia etnoeducativa de San Basilio de Palenque, Departamento de Bolívar, en la década de los 80 se planteó esta guía metodológica como un experimento, donde se desarrolló este proceso de construcción del método.

El espacio más expedito por excelencia, habilitado para poner en escena al método de la consulta a la memoria colectiva, lo constituye la Fundación "Instituto de Educación e Investigación Manuel Zapata Olivella", iniciativa de educación técnica, pero que adelanta programas profesionales en convenio, surgida en el año 2003, en el seno del Proceso de Comunidades Negras, Palenque Regional Ku Suto - PCN. El sistema de investigación del Instituto, los grupos y semilleros de investigación y las líneas que los orientan, constituyen los escenarios para la practicabilidad del método, haciéndolo efectivo en los trabajos de grado, proyectos de investigación, seminarios, talleres y cursos metodológicos.

3 Hernández, R. (2018). En el ensayo: Proceso Histórico de construcción de conocimientos, desde una concepción de epistemologías diferentes y conectadas con los saberes ancestrales, realiza un análisis amplio del proceso de construcción histórica de conocimientos. 
Los desafíos que entrañaban una educación alternativa, una investigación garante de transformación social y la movilización permanente por la defensa de los derechos étnico-culturales, requerían de la institucionalización de un espacio como el instituto, habilitado para contribuir a la generación de dispositivos de resistencia, desde la educación, en el marco del sistema imperante.

\section{Fundamentos del método de la consulta a la memoria colectiva}

Los fundamentos del método corresponden a los grandes pilares o estructura que sostienen el andamiaje investigativo, orientador del cómo, el por qué y el para qué de la investigación. De igual forma, están en correspondencia con el mandato de los procesos históricoculturales de la comunidad. En términos generales estos fundamentos son:

\section{Comunidad como sujeto}

El trabajo comunitario desde las perspectivas de los pueblos afrodescendientes tiene como fundamento el quehacer de las comunidades y, específicamente, su proyecto global de vida o plan global de vida ${ }^{4}$ como herramienta que marca el derrotero en el presente y futuro a partir de una relectura del pasado que igualmente se incorpora a los tiempos anteriores, reafirmando de esta manera la dimensionalidad cíclica de la temporalidad de esta colectividad.

En correspondencia con lo anterior, constituyen las comunidades el sostén en todos los aspectos del trabajo y no se trata de sustituirla a través de iniciativas individuales, por el contrario, lo que se pretende es fortalecer su capacidad colectiva-autónoma para gestionar el conjunto de derechos que le asisten como colectividad

$4 \quad$ Hernández, Simarra et al (2004), definen el proyecto global de vida, o plan de vida como una radiografía del proceso histórico de la comunidad, que busca indagar cómo es la población, cómo era antes y cómo se proyecta para el futuro, en términos de las ventajas y problemáticas que presentan las comunidades. El plan de vida se puede considerar como un conjunto de valores que caracterizan los perfiles de sociedad y de las personas que las poblaciones étnicas quieren construir. Así mismo, fortalece la vida comunitaria, reafirma y reconstruye la identidad personal y social. 
étnica diferenciada, movilizando sus energías para encarar las dificultades y obstáculos que se presentan en su cotidianidad.

La capacidad-colectiva-autónoma se dinamiza mediante un conjunto de expresiones organizativas que tienen establecido unos fines, propósitos y alcances específicos que encarnan las aspiraciones de las comunidades, en correspondencia con sus necesidades e intereses.

La condición de sujeto actuante se manifiesta en la concordancia del trabajo con todas las esferas de la realidad en que están inmersa las comunidades, su visto bueno a los procedimientos que se definen, su aprobación a los resultados que se logran, el disfrute del cumplimiento de los propósitos, las sanciones frente a los errores y fracasos que se cometen y la interiorización como opción de desarrollo de la experiencia acumulada. En este sentido, los planes, programas y proyectos están subordinados a las decisiones de la comunidad, su sentir y actuar particular en consonancia con las circunstancias históricas prevalecientes.

\section{Sabiduría ancestral y cultura}

La cultura afrocaribeña tiene distintas manifestaciones y compromete diversas esferas de nuestra realidad social, económica, política y cultural. El núcleo principal de sus relaciones sociales es la familia extendida, caracterizada por la existencia de troncos familiares bastante numerosos, unidos a través de lazos de parentescos, vínculos culturales que trasciende lo consanguíneo y dan primacía a otros elementos propios de la prole.

Estas familias constituyen el centro de un conjunto de manifestaciones identitarias en el campo de su religiosidad, mitología y creencias; música, rítmica y lúdica; lengua, tradición oral y expresividad; formas jurídica y sistema de derecho propio; territorio y territorialidad, ambiente y sistema tradicional de producción.

Este mundo cultural está permeado por una concepción de tiempo no lineal y más bien circular mediada por las relaciones con la naturaleza y los acontecimientos más importantes que ocurren en el devenir de la población e inciden en un ir al pasado y regresar 
permanentemente al presente, mirando el futuro, es decir, una articulación permanente de los tiempos a partir de las circunstancias propias del mundo de la vida.

Alrededor de muchos de estos componentes de la cultura Afrocaribe, surgen distintas expresiones organizativas que de una $u$ otra forma ayudan a la reafirmación de los referentes identitarios y constituyen, más allá de su quehacer específico, auténticos escenarios de socialización, construcción, articulación cultural-organizativa, y conocimiento de la realidad.

Entre estas formas organizativas culturales, sobresalen los múltiples y diversos grupos musicales y de danza que existen a lo largo y ancho de la región Caribe, entre los cuales los más importantes para Hernández (2014) son:

Las Cantaoras, y los distintos grupos de Bullerengue de Córdoba, Bolívar, Magdalena y Sucre, el Joe Arroyo y su orquesta la verdad, los distintos grupos de guacherna que integran el carnaval de Barranquilla con Pedro Ramayá Beltrán a la Cabeza, las danzas africanas que desfilan durante el Carnaval de Barranquilla, los cantantes de son afrocaribeños entre estos el Sexteto Tabalá, los recientes grupos de champeta con Anne Swin, los Astros, la tripleta palenquera integrada por Charles King, Lowis Tower y Melchor Torres. También surgen los distintos grupos organizativos pesqueros, como el comité de pescadores de Puerto Santander y Asopesca en Marialabaja, departamento de Bolívar, la Asociación de Pescadores de La Boquilla en Cartagena, de Tolú (Sucre) y Puerto Escondido (Córdoba)..Complementan el panorama, las organizaciones de agricultores y mineros que recrean su cultura a la orilla del río, de la mina o la pequeña parcela de tierra al son de la música y de la cosmovisión religiosa de origen africano y entre las que mencionamos: El Bullerengue, Bunde el son de negro, el mapalé entre otras (pp. 69-70). 
Desde el punto de vista de la socialización pública de la cultura, los festivales y carnavales se han convertido en el principal factor aglutinador caribeño, al generar todo un despliegue o movilización social a su alrededor. El investigador musical Enrique Muñoz (2007) lo dice de la siguiente manera:

Las fiestas son síntesis sociales, históricas y culturales de las comunidades humanas; en ese contexto, hay que estimar sus saberes y lenguajes simbólicos que se proponen a partir de la oralidad y la documentación de archivos. La comprensión e interpretaciones de los contenidos culturales de los diversos saberes del pueblo son los elementos integradores de sociedad e individuo en sus relaciones locales, regionales, nacionales y globales, dimensiones en las que se intercambian bienes simbólicos que crean, recrean e invierten el capital cultural. (p. 434)

El papel transgresor de las fiestas y carnavales es tan evidente y refleja una profunda sutileza estética admitida por todos los conglomerados populares como algo natural y auténticamente transformador de mentalidades, al menos así lo testimonian el Carnaval de Barranquilla, definido como la subversión festiva de la cotidianidad insípida y rígida, así sea solo durante el tiempo fugaz de los festejos (Rey, 1992).

En un análisis del discurrir histórico de las fiestas del 11 de noviembre en Cartagena, el mismo Muñoz (2007) afirma que:

Las fiestas destruyen el discurso hegemónico y proponen casi siempre, un discurso crítico, señalan lo que desde la esfera del poder se considera invisible. La simbología del regocijo patrio lo convierte en visible, ese es el gran mérito de lo devela la mascarada carnavalesca, mostrar y hacer mirar al otro, lo que no ve en su cotidianidad (pp. 435-436).

Desde estas perspectivas, las fiestas constituyen un mecanismo certero para construir contra hegemonía concebido como la capacidad para generar consenso alrededor de lo distinto a lo dominante como expresión concreta de lo hegemónico. 


\section{Participación comunitaria}

Los anteriores fundamentos establecen las bases de la participación durante los distintos momentos del trabajo, el cual debe tener presente que se habla de participación en el ámbito comunitario propiamente dicho, y todo lo que esto encierra en materia de reconocimiento y cumplimiento de derechos como colectividad étnica o colectividad social. Igualmente, tiene una manifestación clara en el terreno del ejercicio de la ciudadanía y sus derechos como persona y ser social, siendo su mayor expresión la participación política electoral.

La participación para los pueblos afrodescendientes implica según Hernández (2014, pp. 75-76) lo siguiente:

- Tener como asidero las decisiones de la comunidad entorno a su quehacer recogido en los instrumentos que dispongan, trátese de planes, programas o proyectos.

- En todos los momentos del proceso desde la formulación, ejecución y evaluación, las comunidades constituyen el soporte fundamental de lo que se realiza.

- La confrontación posterior representa también un momento clave que blinda la participación de la comunidad en la medida que posibilita revisar lo concebido, lo implementado y los resultados alcanzados con la nueva realidad de las comunidades.

- El fundamento mayor de la participación de las comunidades Afrodescendientes está vinculado al concepto de ciudadanía como sujetos políticos que ejercen derechos colectivos indistintamente de su condición urbana o rural.

Sea cual fuere el momento, se coincide con la Mesa Nacional de Educación Rural (2017) en que la participación implica: voluntad, información, igualdad desde las diferencias, organización, decisión, creatividad y legitimidad. 


\section{Pedagogías propias y su relación con el método}

Las pedagogías propias están constituidas por prácticas y mecanismos construidos históricamente por la comunidad y constituyen la forma predilecta de educar a sus hijos e hijas, entre estos dispositivos resaltamos el consejo de los mayores, la narración de vivencias por los padres y algunos propios del aprendizaje lúdico.

Para Rodríguez y Muñoz (2014) todos estos elementos están cruzados por la tradición oral que caracteriza la cultura de las colectividades étnicas y culturales, la cual permite reproducir de generación en generación la sabiduría ancestral que reposa herméticamente en la memoria colectiva y que aflora acorde con las circunstancias que moldean su sentir, pensar y actuar.

El método enriquece y fortalece las pedagogías propias en la medida que permite revelar situaciones propias de la realidad, aportando a la renovación de los conocimientos sobre esta y facilitando el uso y apropiación del uso de los elementos didácticoscomunitarios de las pedagogías propias y, a su vez, las pedagogías propias facilitan el cómo implementar el método, propiciando su apropiación, socialización y manejo.

\section{Transformación de realidades}

La investigación no es un capricho o deseo de quienes la implementan, responde a una intencionalidad clara y propósito de búsqueda de alternativas a problemáticas de las comunidades. El problema se entiende según Hernández (2014):

... como obstáculo que impide satisfacer unas necesidades determinadas como colectividad étnica que participa de un conjunto de relaciones sociales, económicas, políticas, territoriales y culturales propias de su existencia como ser y requerimiento de su estar. La necesidad hace alusión a lo que de manera obligatoria tienes que acceder, hacer, usar y consumir para llenar unos vacíos que dificultan tener una vida como colectividad humana y específicamente como conglomerado culturalmente definido (p. 74). 
Estos problemas y necesidades no lo inventa el agente comunitario, sino que surgen y se desarrollan en la realidad, convirtiéndose también, en una necesidad, su identificación para su tratamiento en términos de solución de este, como factor garante de un mayor desarrollo.

Los problemas se solucionan de manera coyuntural, es decir, momentáneamente, o se resuelven totalmente, teniendo en cuenta el origen y tiempo de existencia, de esta manera, adquiere una dimensión estructural, entendida como lo que nace y se mantiene inherente a una personalidad histórica-cultural o a un tipo determinado de relaciones sociales y étnico-culturales.

\section{Camino metodológico que conjuga la consulta a la memoria y la recuperación colectiva del devenir histórico-cultural}

Desde las perspectivas de Rodríguez et al. (2016) son muchos y diversos los interrogantes que debemos hacernos para explicar el camino a seguir desde el punto de vista del método y su funcionabilidad histórica.

Entre estos interrogantes, se destaca: ¿Cómo convertir la investigación en una herramienta y no en una camisa de fuerza? La respuesta a este interrogante la encontramos al ordenar una propuesta de método de consulta a la memoria y a parir de allí organizar las actividades para la historia colectiva. Por consiguiente, existe un conjunto de herramientas que desempeñan un papel importante en la construcción de conocimientos, actuando como recolectores, soportes y también especie de dispositivos que captan y facilitan seguir la ruta trazada por el horizonte metodológico.

\section{Las herramientas}

Los sentidos, la imaginación y la creatividad son los engranajes que ponen a funcionar el mecanismo para comprender una manera de entender el mundo, el propio mundo y el de todos. Con los sentidos se recogen las informaciones, con la imaginación, se relacionan y, con la creatividad, se expresan. Son las herramientas más inmediatas y corresponden a nuestra dotación biológica como especie. 
Los sentidos son el sujeto que asume sus sentidos como una herramienta de conocimiento. Conoce desde lo subjetivo y lo universaliza desde lo objetivo. Los sensores de la memoria son las fuentes de información más inmediata y variada, desde donde se parte para la ampliación progresiva de los referentes.

La imaginación es esa facultad de la inteligencia que permite relacionar y ampliar las referencias hacia una comprensión mayor.

La creatividad se manifiesta como la posibilidad de la expresión de lo más concreto a partir de los fenómenos y hechos más particulares que se traspolan hacia lo macro desde su mínima expresión.

La materia prima son los recuerdos en el tiempo, las huellas de la especie humana, las comunidades como lo específico, es la consulta en todos los indicios que están en las huellas y recuerdos, desde la fuente tradicional impresa hasta la huella de los olores y sabores.

Los ejes de la articulación son el sentido de pertenencia como punto de partida de la identidad.

La relación micro-macro, se entiende en lo pequeño y se universaliza en lo grande, la misma esencia del fenómeno o el hecho que traspola.

La relación individuo-colectivo, a partir de entenderse como individuo, se reconoce conscientemente como colectivo. En esta categoría se ubica la dimensión de sociedad civil.

La relación concreto-abstracto, para articular la precisión de los fenómenos, es fundamento para la articulación de la síntesis.

\section{Fases de la investigación}

Con estas herramientas como base, se divide el proceso de la investigación en cuatro fases a saber: Sensibilización y acercamiento; indagación y articulación; síntesis y expresión, concluyendo con la confrontación.

Durante estas cuatro fases, el proceso de comprensión y entendimiento de la realidad, como práctica socio-cultural, tiene presente el papel de los sentidos, la imaginación, la intuición, las 
dudas, alertas, sueños, creaciones, recuerdos y el intelecto como expresión de reencuentro con los acontecimientos propios del discurrir histórico cultural de la comunidad, constituyendo referentes analíticos del cual derivan conocimientos.

Con el desarrollo de estas fases, se evidencia aún más la importancia de una ruta metodológica como la aquí planteada, rompiendo de esta manera con la concepción monológica, anclada en el racionalismo occidental, y sus perspectivas negadoras de otras racionalidades, tal cual como lo expresa Senghor (1970) citado por Wimmer (1996), quien consideró:

El trato característico de la filosofía cartesiana, es una relación distante y objetiva entre el sujeto que piensa y la realidad. Esta razón por los ojos, diferencia entre el sujeto y el objeto, y analiza la esfera de los objetos de modo sobrio y calculante, que es característica del francés o, en general, de los occidentales. Esta variedad de razón objetiva es interpretada como superior, comparada con cualquiera alternativa en algunas esferas de la actividad humana, especialmente las ciencias y en la tecnología. Por otra parte esta 'razón de los ojos' reduce las posibilidades de la emocionalidad humana y de la vida social, si es practicada de modo exclusivo. Por eso, el complemento de la razón de los ojos, llamados "razón del abrazo "por Senghor, no es forma inferior de la razón, sino por el contrario una forma igualmente necesaria y es presentada por el negro" (p. 11) .

\footnotetext{
$5 \quad$ Cuende (2008) en su tesis doctoral titulada: La perspectiva filosófica de Leopoldo Sedar Senghor sobre el ser humano y su vinculación al existencialismo, sustenta ampliamente el ideal de razón de abrazo como parte del pensamiento de Senghor en contraposición al pensamiento occidental y en particular del representado por Descartes y su concepción cartesiana. Mientras que la razón discursiva, la razón ojo del blanco, se detiene ante las apariencias del objeto, la razón intuitiva, la razón abrazo del negro, por encima de lo visible, llega hasta la realidad profunda del objeto, para captar su sentido, más allá del signo. De esta manera para el negro-africano, todo objeto es símbolo de una realidad más profunda, que constituye el verdadero significado del signo que nos es dado en primer lugar. Toda forma, toda superficie y línea, todo color y detalle, todo olor, todo aroma, todo sonido, todo timbre, todo tiene su significado, (p. 75).
} 
Por consiguiente, desde diferentes racionalidades se comprende e interpreta el mundo y contemplan rutas investigativas propias que se sincronizan operativamente en el tiempo y en el espacio de manera también diferente o específica, mediante métodos apropiados a la realidad de las colectividades.

\section{Fase de sensibilización y acercamiento}

La sensibilización es la apertura al conocimiento desde los sentidos y la propia lógica, se inicia el reconocimiento con mente abierta, y la imaginación es el principal aliado. Los sentidos con la imaginación creando y entendiendo. El acercamiento es amistad, y en su crecimiento se concreta el contacto dialógico. Para la sensibilización es clave comprender el sentido de la vida, la memoria, el olvido y la muerte, como referentes claros que permiten comprender el sentido del tiempo y en términos generales, pulsarlo.

Mediante la sensibilización, se busca pulsar los recuerdos y generar un ambiente cultural de confianza y articulación como condición indispensable que facilita una mirada desde la propia lógica de la comunidad como sujeto del proceso investigativo.

Las actividades que se realizan en esta fase con los miembros de la comunidad, deben incluir ejercicios prácticos o técnicas para la identificación de olores y sabores como opción de auto reconocimiento en su mundo cultural. Igualmente, incluye narraciones de historias familiares, cuentos, canciones que motiven los recuerdos y permitan generar elementos para ir tejiendo sucesos e interpretar el ritmo cotidiano.

\section{Fase de indagación y articulación}

En esta fase se mantiene la pulsación de recuerdos a través de canciones, fotografías, olores y sabores para reconstruir historias familiares, tejer sucesos y contar vivencias propias de la cotidianidad.

La comunidad es quien convoca a dimensionar sus problemáticas y direccionar su propio desarrollo, mediante ejercicios participativos de autodiagnóstico de la problemática que lo afecta. Para el desarrollo del autodiagnóstico, la indagación se nutre de los componentes de la 
vida de la comunidad en sus aspectos histórico, formas lingüísticas y tradición oral, recursos naturales y ambiente, tradiciones, música, baile, arte, gastronomía, tecnología, vivienda, religión, salud, deportes y recreación, territorio, servicios públicos, población y organización, persona-familia-comunidad, situación económica, perspectiva de género, pedagogías propias.

En la continuidad del proceso de indagación se encuentran aspectos de la vida de la comunidad, así como ejes articuladores que se ubican en el plano de las problemáticas, y los que están en el orden de las potencialidades (estudiando sus manifestaciones, causas, o riquezas). A partir de esas reflexiones, la comunidad establece la visión futurista o aspiraciones de larga duración, incorporada a su proyecto político, social, cultural y económico como colectividad étnica.

\section{Fase de síntesis y expresión}

Con la síntesis se logra la primera y definitiva decantación, para que los ajustes, pulimentos y reconocimientos, y las nuevas indagaciones, se reciclen poniéndolos como espejos y se logre expresar una lectura de reconocimiento.

Una vez hecho el recorrido en las indagaciones por las problemáticas y proyecciones de la comunidad, se detectan aspectos puntuales en los que se priorizan realidades y luego se procede a proyectar la visión futurista o proyecto de sociedad, esto se logra precisamente con lo encontrado en el proceso de inspección preliminar o diagnóstico.

Por lo tanto, el proceso de indagación comunitaria en la construcción del plan global de vida, expresa los elementos indicadores de los ideales comunitarios, en los diferentes campos: la concepción de sociedad, el sistema de creencias, concepción filosófica y antropológica del mundo y el tipo de persona que requiriere esa población, su nivel de vida, evidenciándose los énfasis a partir de aspectos cruciales de esa colectividad tanto en el campo espiritual como material. 


\section{Fase de confrontación}

En esta fase la investigación regresa nuevamente a la comunidad, como sujeto constructor de conocimientos y legitimador del conjunto del proceso investigativo. La comunidad desde su sabiduría valida los productos y resultados de la investigación como alternativa al problema investigado y opción de su devenir futuro.

En ese sentido, es importante tener presente lo que dice Guerrero (2008) en relación con el papel de la confrontación y socialización:

esta fase es fundamental en un proceso de investigación colectiva, pues es allí donde el "espejo revelador" se presenta en toda su dimensión y la comunidad se refleja y se desvela a sí misma (pp. 195-196).

De esta manera, la comunidad se apropia de la investigación, lo incorpora a su ideario soportado por el plan global de vida, traduciéndolo en acciones concretas a favor de su bienestar colectivo.

\section{Ejes de conocimiento}

Los ejes de conocimiento fundamentan el engranaje de las actividades. Se ordenan siguiendo el mismo principio epistemológico del método propuesto, su duración previsible está sujeta al ritmo de aprendizaje y asimilación de la comunidad.

\section{Eje de manejo teórico de la herramienta metodológica}

Al manejo teórico corresponden los ejes ¿Qué es la Historia? y mentalidad y memoria colectiva. El primero pretende acercar el concepto de historia confrontando diferentes categorías y manejos conceptuales dentro de la historia tradicional y la historia nueva. Construir una definición de historia a partir de la lectura de tiempos. En el segundo eje del manejo teórico, se ubica el espacio de la mentalidad y la memoria colectiva y se hace el entrenamiento para la consulta de la memoria y la conciencia de la propia lógica como un ejercicio conceptual. 


\section{Eje de manejo sensible de la herramienta}

Tiene como referencias principales todo lo que encierra y significa la fase de sensibilización, complementada con las historias familiares. En la sensibilización se parte del cuerpo humano como una herramienta de conocimiento. Cada sentido es un camino para encontrar indicios y se reconoce la subjetividad como surco de entrada a la indagación. Las historias familiares acercan a la dimensión de ser sujeto histórico y su autorreconocimiento en su discurrir histórico propio, pero en clave de diálogo con los acontecimientos de la historia nacional, donde igualmente desempeña un papel protagónico.

\section{Eje de utilización práctica de la herramienta}

Este eje tiene como escenario predilecto, la fase de indagación y seguimiento, tendiente a recoger participativamente la información necesaria para la construcción de conocimiento y, a su vez, aprender colectivamente de toda la ruta que se adelanta. En la indagación se pone en funcionamiento lo aprendido en las actividades de manejo de los ejes anteriores. Se tienen los elementos mínimos con los cuales se inicia el proceso de la investigación, y la comunidad ya está investigando y articulada a todo el proceso. Este es el aspecto más largo y sirve de termómetro medidor del aprendizaje, de allí la importancia del seguimiento.

\section{Eje de confrontación}

La confrontación es la clave de las actividades, en la medida que brinda la oportunidad para la apropiación y legitimación de la dinámica investigativa por la comunidad. Aquí la comunidad se mira en el espejo que ha construido y se da tanto el reconocimiento como la manera de reciclar y transformar el resultado. Aquí se pretende que logre conciencia del método y los caminos para la autogestión en el conocimiento.

Para Rodríguez et al (2016) durante las fases y sus ejes pragmáticos, el método de consulta a la memoria colectiva, dispone de formas de conocimiento como el análisis de coyuntura, la evaluación permanente de las actividades y la misma sistematización 
que posibilitan conocer desde perspectivas de corta duración la realidad y proyectar con los sujetos comunitarios acciones para su transformación.

A la luz de este análisis, y a manera de reflexiones finales, decimos que el método de consulta a la memoria colectiva y su concepción de las comunidades como sujeto, objeto y fuente de investigación, constituye una ruta y opción metodológica que empodera epistemológicamente a las colectividades étnicas y, en particular, a la población afrocolombiana, negra, raizal y palenquera y étnica en general. Ellas requieren de horizontes epistemológicos que le devuelvan su dignidad y fortalezcan su condición de sujeto epistemológico forjador de sociedades centradas en derechos colectivos como soporte de democracias reales, que responden a concepciones e ideales del Buen Vivir y del Ubuntu. Estos propósitos se leen en clave de diálogo con otras alternativas metodológicas como la IAP, la sistematización etnográfica y otras que responden también al ideal de indagar desde las lógicas propias de las comunidades étnicas y sociales, y avanzar en el fortalecimiento de saberes ancestrales como savia que alimenta y sostiene sus epistemologías propias.

\section{Referencias}

Cuende, M. (2008). La perspectiva filosófica de Leopoldo Sedar Senghor sobre el ser humano y su vinculación al existencialismo. Tesis doctoral. España. Universidad de Oviedo. Departamento de Filosofía. Recuperado de www.africafundacion.org/Maria_jesus_Cuende_Senghor.Tesis doctoral.

Fals Borda, O. (1998). Investigación Acción Participativa. Aportes y desafíos. Dimensión educativa. Santafé de Bogotá, D. C.

Feyerabend, P. (1984). Contra el método. Esquema de una teoría anarquista del conocimiento. Barcelona. Editorial Orbis.

García Márquez, G. (1982). Discurso de aceptación del Premio Nobel: La soledad de América Latina. Recuperado el 20 de agosto de 2018, a partir de https://cvc.cervantes.es/actcult/garcia_ marquez/audios/gm_nobel.htm 
Guerrero, C. (1998). Palenque de San Basilio: Una propuesta de interpretación histórica. Universidad de Alcalá de Henares. Facultad de Filosofía y letras. Departamento de Historia. Área de Historia de América.

Hall, S., \& Dugay, P. (2003). Cuestiones de identidad cultural. Buenos Aire: Amorrortu.

Hernández, D., Simarra, R., y Hernández, R. (2004). Enfoques y caminos en la construcción de procesos de etnoeducación. Cartagena. Secretaría de Educación Distrital de Cartagena.

Hernández, R. (2014). Movimientos sociales, identidad y sujetos de poder. Cartagena. Instituto Manuel Zapata Olivella.

Hernández, R. (2018). Proceso histórico de construcción de conocimientos. En: Saberes ancestrales, epistemologías propias e interculturalidad epistemológica. Cartagena. Inédito.

McNay, L. (1994). Foucault: A Critical Introduction. Cambridge. Polity Press.

Mantilla, W. (1999). El Científico y la Ciencia II. Bogotá. UNAD.

Mesa Nacional de Educación Rural. Secretaría Técnica (2017): Documento Propuesta sobre la Mesa Nacional de Educación Rural orientadas al desarrollo del sector rural y sobre la metodología para la participación. Bogotá.

Muñoz, E. (2007). Cartagena Festiva. Cartagena. Corporación Concurso Nacional de la Bella.

Rey, E. (1992). Joselito Carnaval. Barranquilla. Editorial caballito de mar.

Rodríguez L., Hernández, R., et al. (2016). Método de la consulta de la memoria colectiva y perspectiva de la investigación. Cartagena de Indias.

Rodríguez, L., \& Muñoz, S. (2014). Tradición oral y pedagogías propias. En: Etnoeducación, interculturalidad y pedagogías propias. Rubén Hernández, Compilador. Cartagena. Instituto Manuel Zapata Olivella.

Senghor, L. (1970). Libertad: negritud y humanismo, (traducción de Julián marcos). Madrid. Tecnos. 
Wimmer, F. (1996). Filosofía Intercultural: ¿Nueva disciplina o nueva orientación de la filosofía? En: Revista de Filosofía XXXIII. San José, Costa Rica. 